\title{
Atrial stenting: case based elaboration of indications.
}

\author{
Neeraj Awasthy \\ Department of Pediatrics Cardiology, Max Hospital Saket, Delhi, India. \\ Corresponding Author: \\ Neeraj Awasthy \\ Department of Pediatric and Congenital Heart Surgery, Max Hospital, Saket, New Delhi, 110017. \\ Email: n_awasthy@yahoo.com \\ ORCID ID NO: 0000-0001-60194693
}

Cite this article as: Awasthy N. Atrial stenting: case based elaboration of indications. Nepalese Heart Journal 2020; Vol 17 (1), $41-43$

Submitted date: $1^{\text {st }}$ March 2020

Accepted date: $8^{\text {th }}$ April 2020

\section{Abstract}

\begin{abstract}
In certain forms of congenital and acquired heart defects, wide interatrial communication is important to maintain hemodynamics. In comparison to balloon septostomy or blade septostomy, atrial septal stenting provides a controlled, predictable, and long-lasting atrial communication particularly in children and older age groups. Even though there are theoretical high risks of embolization, atrial stenting proves to be an effective palliative method. We describe 3 cases that underwent atrial stenting for different hemodynamic reasons. All three cases had different age groups. Two of them were moribund sick. Cases were performed under general anaesthesia with the help of transthoracic and transesophageal echo. Since it is uncommon procedure, we hope that this paper will the help in understanding clinical applications.
\end{abstract}

Keywords: Atrial stenting; mitral atresia; pulmonary artery hypertension; transposition of great arteries.

DOI: https://doi.org/10.3126/njh.v17i1.28808

\section{Introduction}

Atrial septal stenting is done in selected congenital heart diseases where left atrial decompression, inter circulatory mixing, and maintenance of cardiac output are dependent on the size of the atrial septal defect.This paper describes three different hemodynamic indications for which atrial stenting have been performed.

\section{Case Reports}

Case 1

A 10 months old child with the weight of $6 \mathrm{~kg}$ presented to us in a very sick state. He was intubated for cardiorespiratory arrest and transferred to us on intermittent positive pressure ventilation after resuscitation. Echocardiography showed situs solitus, restrictive PFO, atrioventricular (AV) concordance, ventriculo arterial (VA) discordance, perimembranous ventricular septal defect (PMVSD) which was closed with septal tricuspid valve leaflet prolapse. Left ventricular outflow tract obstruction (LVOTO) was present due to the prolapsing tricuspid valve leaflet. There was no flow noted across the ventricular septal defect (VSD). The LVOTO prepared the left ventricle (LV) for possible switch (LV mass of 54gram/ $\mathrm{m}^{2}$ against, posterior wall: $5.8 \mathrm{~mm}$ ). After initial stabilization and treatment of sepsis, he continued to have thrombocytopenia and hence was not suitable for surgery. The child was having an oxygen saturation of $45 \%$ with high lactate levels of 5-8 mmol/l. He underwent atrial ballooning with atrial septal stenting (Dynamic peripheral stent, premounted, $9 \mathrm{~mm} \times 25 \mathrm{~mm}$ ) to improve intracardiac mixing. The child improved symptomatically after the procedure, his saturation rose to $85 \%$ and the serum lactate level normalized. He was extubated on $4^{\text {th }}$ post-procedure day. He was discharged after hemodynamic stabilization. He underwent arterial switch repair with atrial stent extraction after 15 days. His post-operative parameters remained stable.

@ Nepalese Heart Journal. Nepalese Heart Journal retain copyright and works is simultaneously licensed under Creative Commons Attribution License CC - By 4.0 that allows others to share the work with an acknowledge of the work's authorship and initial publication in this journal 
Figure 1: Case 1 with AP view under fluoroscopy showing the deployment of the stent

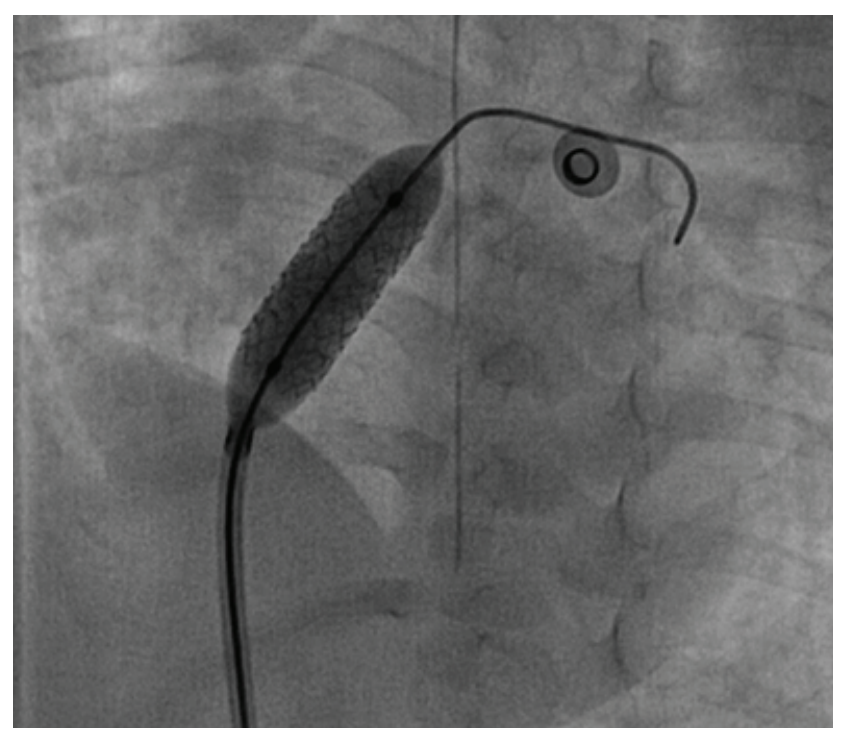

Figure 2: 2 D echocardiography with subcostal coronal view showing the stent in situ in case 1 .

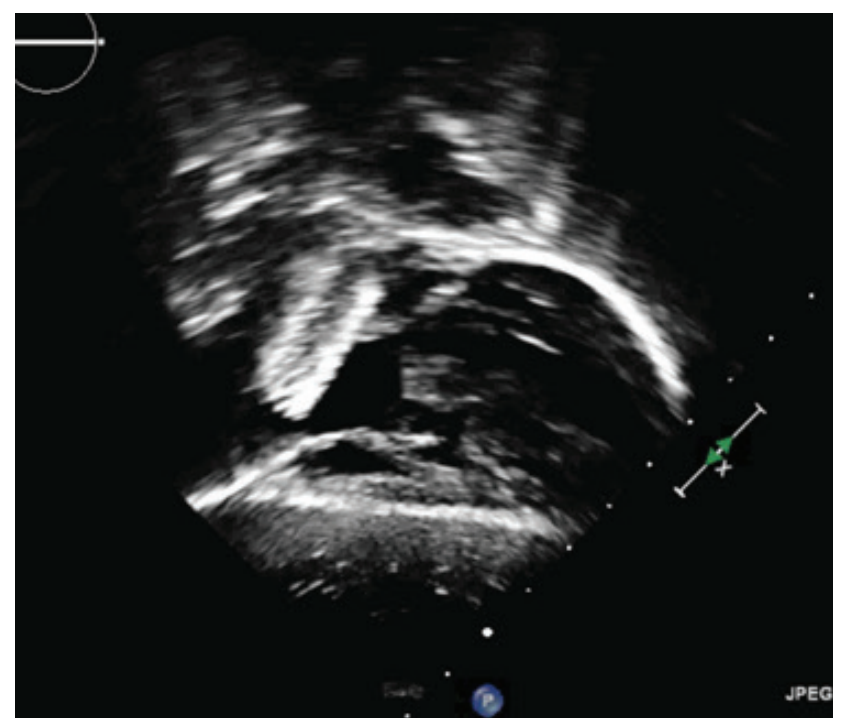

Case 2

An 11 years old female having symptoms of easy fatigability, and mild cyanosis was referred to us for evaluation. Echocardiography showed situs solitus, univentricular atrioventricular (AV) connection, L-loop ventricles, Tricuspid atresia, dilated left atrium with restricted PFO shunting left to right and interatrial septum bulging to the right, hypoplastic right ventricle (RV), large muscular VSD, VA discordance, L-posed aorta with moderate pulmonary stenosis (Pressure gradient $=60 \mathrm{mmHg}$ ). She underwent cardiac catheterization to evaluate for suitability for the primary Fontan procedure. She was found to have post-capillary pulmonary hypertension with mean Left Atrial (LA) pressure of $32 \mathrm{mmHg}$ with a mean pulmonary pressure of $38 \mathrm{mmHg}$ as shown in table 1. Patient underwent Atrial Septal
Ballooning with atrial septal stenting with premounted Omnilink Elite $9 \mathrm{~mm} \times 29 \mathrm{~mm}$ peripheral stent. Post-procedure her LA mean pressure decreased to $17 \mathrm{mmHg}$, although pulmonary artery pressures was 28 $\mathrm{mmHg}$. The patient was discharged the next day with the advice of follow-up after 1 year for reassessment.

Figure 3: 2 D echocardiography with color flow mapping showing the presence of right to left shunt with Valsalva maneuver in case 2 .

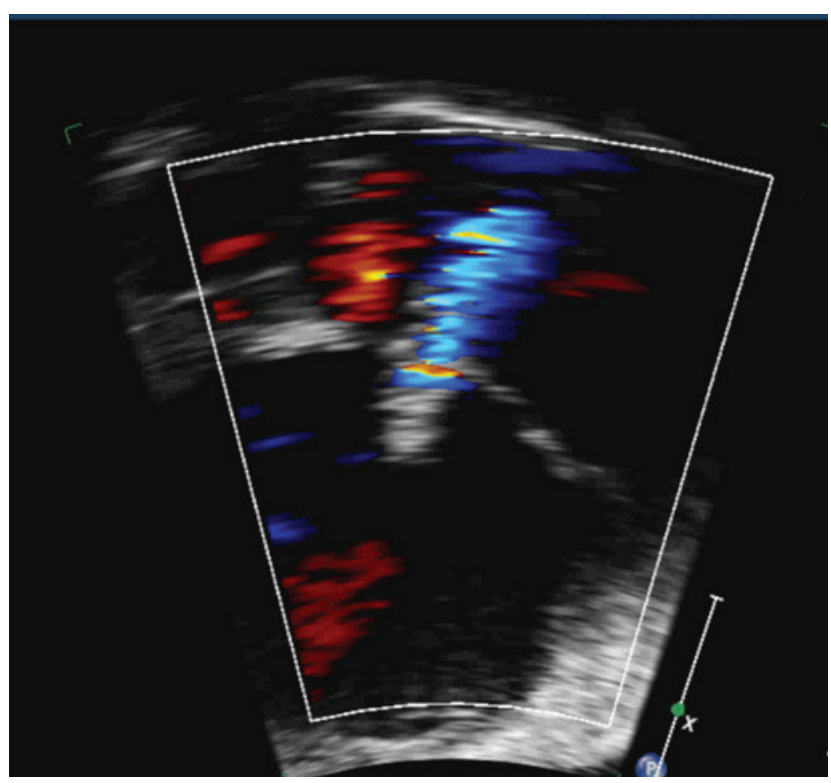

Table 1: Case 2

\begin{tabular}{ll} 
Chamber & Pressure (mmHg) \\
\hline Pulmonary artery & $45 / 22 / 38$ \\
\hline Left atrium & 32 (mean) \\
\hline Descending Aorta & $110 / 72 / 92$ \\
& \\
Case 3 & \\
\hline 45 yrs old male was a diagnosed case of primary pulmonary
\end{tabular}
artery hypertension. He presented with breathlessness of NYHA class III-IV for 6 months with increasing bilateral lower limb swelling for 2 months and decreased urine output for 1 month. He was on pulmonary vasodilators (Ambrisantan, Sildenafil) and diuretics (Torsemide, Aldactone) for the last 2 months before being referred to us. Echocardiography showed dilated RA and RV, severe tricuspid regurgitation ( $\mathrm{max} P \mathrm{PG}=80 \mathrm{mmHg}$ ), severe $\mathrm{RV}$ dysfunction with Trans annular plane systolic excursion (TAPSE) of $4.8 \mathrm{~mm}(\mathrm{~N}>17)$, right ventricular fractional area change (RVEF) of $8 \%(\mathrm{~N}>32)$, mild $\mathrm{LV}$ dysfunction $(45 \%)$. He underwent cardiac catheterization and atrial stenting. His cath data is shown in table 2. Atrial septostomy with peripheral vascular premounted stent of $8 \mathrm{~mm}$ x $29 \mathrm{~mm}$ was done. Post stenting echocardiography revealed right to left (R-L) shunt. Post-procedure the patient improved symptomatically became ambulatory, his pedal edema gradually reduced and disappeared. Post-procedure echocardiography showed inter atrial stent in situ with right to left shunt. RV dysfunction was present with no significant change in TAPSE, although IVC respiratory variation was $50 \%$. 
LVEF was $45 \%$. After 3 months of follow-up, there was a marked symptomatic improvement, stent in situ with right to left shunt, there was an improvement in systolic parameters of RV, with TAPSE of $28 \mathrm{~mm}$. LVEF was about $50 \%$.

Figure 4: Case 3 with AP view showing the presence of wire across the interatrial septum after stent deployment.

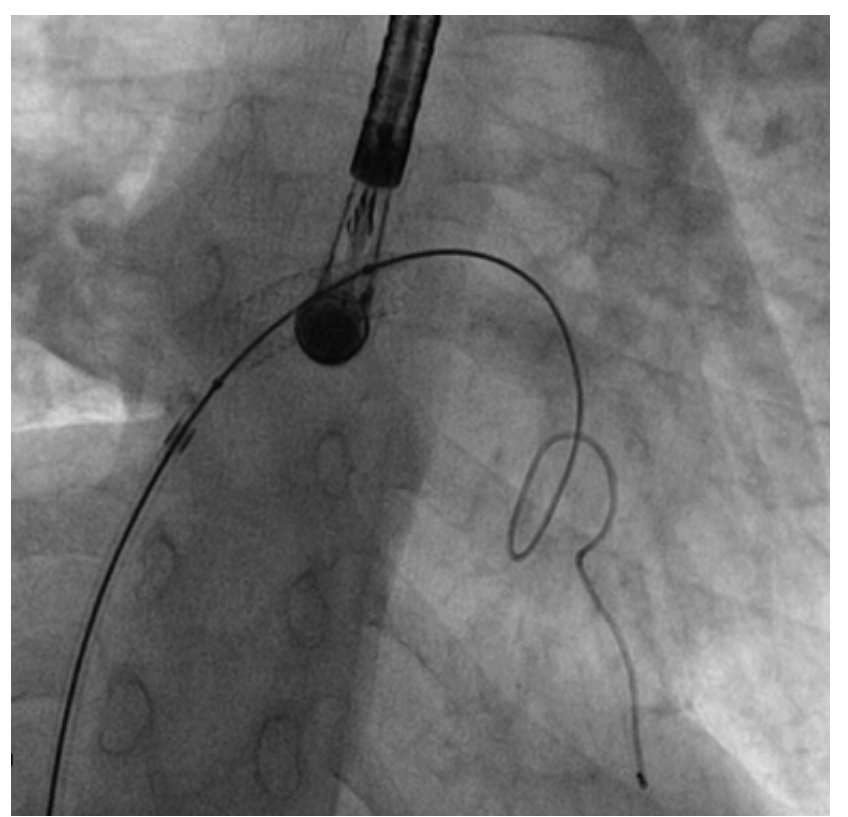

Table 2: Case 3

\begin{tabular}{|ll|}
\hline Chamber & Pressure (mmHg) \\
\hline Right atrium & 24 \\
\hline Right ventricular end diastolic pressure & 22 \\
\hline Descending Aorta & $140 / 88 / 100$ \\
\hline Pulmonary artery & 83 (mean) \\
\hline
\end{tabular}

\section{Discussion}

Atrial septal stenting is done in selected heart diseases where left atrial decompression, inter-circulatory mixing and maintenance of cardiac output are dependent on the size of the atrial septal defect. ${ }^{1}$ The procedure itself is a very uncommon procedure and indications are still evolving. There are various case reports on atrial stenting. Definitive decompression of the left atrium can be achieved by stenting the atrial septum in infants with hypoplastic left heart syndrome. ${ }^{2,3}$ as was demonstrated in our case 2 . The majority of stented ASDs in follow up were observed to be patent, as was confirmed by Doppler echocardiography. ${ }^{2,3}$ Atrial septum stenting is safe and effective in selected cases of congenital heart disease, allowing a reliable, long-lasting, restrictive or nonrestrictive interatrial communication. ${ }^{4}$
Premounted stents have been used to have better control of deployment. There were few cases that reported modifying the shape of atrial stent can ensure better stability and decrease chances of embolization. The diabolo shape increases stent stability, facilitates recrossing of the stent during future catheter interventions, and ensures medium-term stent patency. In a study the technique was employed in 12 consecutive patients to relieve symptoms of a failing Fontan circulation $(\mathrm{n}=6)$ or severe pulmonary hypertension $(\mathrm{n}=$ 6) with no early or late (mean follow up $1.75 \mathrm{yrs}$ ) stent-related complications. ${ }^{5}$ Stent fenestration of the interatrial septum in patients with idiopathic pulmonary arterial hypertension improves the quality of life of patients and can be a bridge to lung or heartlung transplantation. This was the objective in our third case.

We report here three cases who underwent atrial septal stenting for three different hemodynamic reasons. All three had no early complications related to procedure. Child with L-loop ventricles and Tricuspid atresia was discharged with advice to reassess PA pressure after one year. A child with transposition of great arteries underwent Arterial switch surgery with stent explantation. Patients with severe primary PAH improved symptomatically and discharged on oral pulmonary vasodilators. Atrial stenting remains a good option for palliative relief and symptomatic improvement in a variety of congenital and acquired heart disease. The indications and procedure methods are still in evolving phase and more studies and case reports will help in contributing the same.

\section{Disclosure}

The author who is also the member of the international advisory editorial team was not involved in any steps in the editing/publication process.

\section{References}

1. Sivakumar K. Atrial septal stenting - How I do it ?. Ann Pediatr Card 2015;8:37-43. https://doi.org/10.4103/09742069.149516. PMid:25684885. PMCid:PMC4322398

2. Rupp S, Michel-Behnke I, Valeske K, et al. Implantation of stents to ensure an adequate interatrial communication in patients with hypoplastic left heart syndrome. Cardiol Young. 2007;17(5):535-40. https://doi.org/10.1017/ S104795110700090X. PMid:17612414

3. Leonard GT Jr, Justino H, Carlson KM, et al. Atrial septal stent implant: atrial septal defect creation in the management of complex congenital heart defects in infants. Congenit Heart Dis. May;1(3):129-35. https://doi.org/10.1111/j.17470803.2006.00022.x. PMid:18377559

4. Danon S, Levi DS, Alejos JC, Moore JW. Reliable atrial septostomy by stenting of the atrial septum. Catheter Cardiovasc Interv. 2005 Nov;66(3):408-13. https://doi. org/10.1002/ccd.20508. PMid:16216026

5. Stümper O, Gewillig M, Vettukattil J, et al. Modified technique of stent fenestration of the atrial septum. Heart. 2003;89(10): 1227-1230. https://doi.org/10.1136/ heart.89.10.1227. PMid:12975427. PMCid:PMC1767900 